\title{
OS CIGANOS DA COLHEITA
}

\section{THE HARVEST GYPSIES}

John Steinbeck ${ }^{l}$

Tradução

Lucas André Berno Kölln (Unioeste)

Nessa época do ano [no verão de 1936], quando as grandes plantações da Califórnia se aproximam do período da colheita e quando as pesadas uvas, ameixas, maçãs, alface e algodão rapidamente amadurecem, nossas rodovias se enchem de trabalhadores migrantes. Eles são colhedores nômades e pobres, guiados pela fome de plantação à plantação, de colheita à colheita, para cima e para baixo do estado, e até mesmo para algumas partes do Oregon e de Washington, embora seja sobretudo a Califórnia que precise da maioria desses novos ciganos. É um pequeno estudo sobre esses sujeitos errantes que os presentes artigos irão empreender. Há pelo menos 150.000 migrantes sem casa errando para lá e para cá no estado, e isso é um exército grande o suficiente para torná-los relevantes para todos os habitantes da Califórnia.

Ao viajante casual das grandes rodovias, os movimentos dos migrantes podem ser misteriosos se vistos, pois repentinamente as estradas se enchem de precários carros carregados de crianças, roupas de cama sujas e utensílios de

\footnotetext{
${ }^{1}$ Originalmente publicados entre 5-7 de outubro de 1936. Edição utilizada para a tradução: STEINBECK, John. The harvest gypsies: On the road to The grapes of wrath. Berkeley: Heyday Books, 1988. Foram traduzidos os três primeiros artigos da coletânea (de um total de sete). O tradutor agradece a Gayle Wattawa e Emmerich Anklam, editores da Heyday Books, por terem gentilmente permitido a publicação dos presentes artigos.
} 
cozinha enegrecidos pelo fogo - mesmo nas ferrovias os vagões abertos e fechados se enchem de homens. E eis que, tão repentinamente quanto chegaram, eles desaparecem das rotas principais, ao passo que nas beiras de estrada e próximos aos rios onde há pouco viajavam aqueles sujeitos esquálidos, imundos acampamentos de migrantes $^{2}$ são armados, e os pomares se enchem de apanhadores, cortadores e secadores.

A peculiar agricultura da Califórnia requer a existência desses migrantes, e requer que eles sejam itinerantes. Os pêssegos, as uvas, o lúpulo e o algodão não podem ser colhidos pela população local de trabalhadores. Vejase o seguinte exemplo: um grande pomar de pêssegos, que requer o trabalho de somente vinte homens ao longo do ano, mas precisará de dois mil pelo breve tempo de apanha e empacotamento, de tal modo que se a migração dos dois mil não ocorrer, se ela for atrasada uma semana que seja, a plantação apodrecerá e será perdida.

Ainda assim, encontramos na Califórnia uma curiosa atitude em relação a esse grupo que faz nossa agricultura ser bem-sucedida: os migrantes são necessários e odiados. Ao chegarem a um distrito, eles encontram a típica aversão distribuída pelo residente ao estrangeiro, ao forasteiro. Esse ódio em relação ao estranho ocorreu ao longo de toda a história humana, desde os povoados mais primitivos até a nossa altamente organizada agricultura industrial. Os migrantes são odiados pelas seguintes razões: eles são pessoas ignorantes e sujas, eles são portadores de doenças, eles aumentam a necessidade de policiamento e os impostos da educação em uma comunidade, e se lhes for permitido organizarem-se, eles podem, simplesmente por se recusarem a trabalhar, arruinar a safra. Eles nunca são realmente acolhidos em uma comunidade nem em sua vida social. São vagabundos de fato: não lhes é nunca permitido sentir-se em casa nas comunidades que precisam de seus serviços.

\footnotetext{
${ }^{2}$ Optamos por traduzir "squatters" como "migrantes" ao invés de "posseiros" pelo fato de que na maior parte do tempo Steinbeck enfatiza sua condição de itinerância (donde o título de "ciganos da colheita") em detrimento de sua condição de posse de terra. Como essa palavra vem quase sempre na expressão "squatters' camp" (acampamento de migrantes), é quase sempre com esse sentido que ela é empregada: ressaltando a condição errante e não questão de posse e propriedade. (N. do T.)
} 
Vejamos que tipo de pessoas são eles, de onde vieram e quais são as rotas de sua migração. No passado [especialmente no século XIX] eles eram de diversas raças, encorajados a vir aos Estados Unidos e frequentemente importados como mão-de-obra barata: chineses no início, depois filipinos, japoneses e mexicanos. Eram estrangeiros, e, como tal, eram arrebanhados, excluídos e segregados. Se tentassem se organizar, eram deportados ou presos, e, não tendo advogados, nunca conseguiam uma audiência para seus problemas. Nos últimos anos [sobretudo após a deflagração da crise de 1929], entretanto, esses imigrantes começaram a se organizar, e a esse sinal de perigo, foram deportados em grande número, inclusive porque havia uma nova reserva, da qual uma grande quantidade de mão-de-obra barata poderia ser obtida.

A seca no Meio-oeste trouxe populações agrícolas de Oklahoma, Nebraska e partes do Kansas e do Texas para o oeste. Suas terras foram destruídas e esses migrantes jamais poderão voltar para elas. Milhares deles estão cruzando as fronteiras em barulhentos automóveis antigos, destituídos, famintos e desabrigados, prontos a aceitar qualquer pagamento que os possibilite alimentar-se a si próprios e a seus filhos. Isso, aliás, é algo novo no trabalho migrante, pois os trabalhadores estrangeiros eram importados sem seus filhos e sem tudo o mais que restara de sua vida.

Eles geralmente chegam à Califórnia tendo usado todos os recursos que possuíam na jornada, tendo até mesmo vendido os pobres cobertores, utensílios e ferramentas ao longo do caminho para a compra de gasolina. Chegam perplexos e exaustos, frequentemente num estado de semi-inanição, com apenas uma necessidade com a qual lidar imediatamente: encontrar trabalho a qualquer salário, para que sua família possa ter o que comer.

$\mathrm{Na}$ Califórnia há somente um cargo que podem preencher, e um que os torna inelegíveis para o auxílio governamental: eles devem tornar-se trabalhadores migrantes do campo. Pelo fato de o antigo grupo de trabalhadores, mexicanos e filipinos, estar sendo deportado e repatriado muito rapidamente, enquanto, por outro lado, o caudal de refugiados dos dust bowls 
aumenta constantemente, é esse o novo tipo de migrante que devemos considerar centralmente.

Os antigos migrantes, os estrangeiros, foram invariavelmente retirados de uma classe de peões, mas não é esse o caso dos novos migrantes. Eles são pequenos fazendeiros que perderam suas terras ou trabalhadores agrícolas que viviam com suas famílias no antigo estilo americano; homens que trabalharam duro em suas próprias fazendas, que sentiram o orgulho de possuir uma terra e viver em contato direto com ela. São americanos engenhosos e inteligentes, que atravessaram o inferno da seca e que viram suas terras murcharem, morrerem e terem sua superfície varrida. Isto, para um homem que já foi dono de sua terra, é uma intrigante e terrível dor. Esses novos migrantes fizeram a travessia e viram seus filhos morrerem pelo caminho. Seus carros quebraram e foram consertados com a engenhosidade do homem da terra - é comum que remendem os pneus desgastados a cada poucas milhas.

Eles têm resistido e podem resistir muito mais, pois seu sangue é forte. Eles são descendentes dos homens que cruzaram o meio-oeste, que conquistaram suas terras lutando, que cultivaram as planícies e nelas ficaram até que elas voltassem a ser deserto. Devido à sua tradição e ao seu treinamento, eles não são migrantes por natureza, eles são ciganos por força das circunstâncias.

Em suas mentes, conforme eles se movem exaustivamente de colheita à colheita, há um desejo e uma esmagadora necessidade: conseguir uma pequena propriedade novamente, estabelecer-se nela e por um fim à sua itinerância. Caso se queira atestá-lo, basta ir a um acampamento de posseiros onde as famílias vivem sobre o chão de terra sem camas, equipamentos ou um lar. Basta olhar para seus rostos fortes e resolutos, mas cheios de dor e (sobretudo quando vêem as terras ociosas das companhias) de raiva para saber que essa nova raça está aqui para ficar e que atenção lhes é devida.

É preciso que se entenda que com essa nova raça velhos métodos de repressão, de salários de fome, de enclausuramento, de agressão e intimidação não irão funcionar, pois eles são gente americana. Consequentemente, devemos 
tratá-los de forma compreensiva e tentar resolver seus problemas, tanto para o bem deles quanto para o nosso.

É difícil acreditar no que um grande fazendeiro especulador disse certa vez, que o sucesso da agricultura californiana requer que criemos e mantenhamos uma classe de peões. Se for assim, então a Califórnia deve abandonar a aparência de governo democrático que permanece aqui.

Os nomes dos novos migrantes indicam que descendem de ingleses, alemães e escandinavos. Há Munns, Holbrooks, Hansens, Schmidts. E eles são estranhamente anacrônicos em um aspecto: tendo crescido nas planícies onde a industrialização nunca penetrou, eles pularam bruscamente de uma velha e auto-suficiente fazenda, onde quase tudo o que era utilizado crescia ou era manufaturado por eles próprios, para um sistema de agricultura tão industrializado que o homem que cultiva uma plantação não costuma ver, com exceção do período da colheita, o fruto de seu cultivo, onde, enfim, o migrante não tem contato com o processo de crescimento.

Há ainda outra diferença entre sua antiga e sua nova vida. Eles vieram dos pequenos distritos rurais onde a democracia não só era possível como inevitável, e onde a participação popular, fosse ela praticada na Grange, ${ }^{3}$ na organização da igreja ou no governo local, era responsabilidade de todos. Eles vieram para um país onde, por causa do movimento necessário para sobreviver, não lhes é permitido qualquer voto, e onde são considerados uma classe sob todos os aspectos desprivilegiada.

Vejamos as lavouras que requerem seu trabalho e os distritos para onde eles devem viajar. Como um garotinho em um acampamento de posseiros disse: "Quando eles precisam de nós, eles nos chamam de migrantes, e quando

\footnotetext{
${ }^{3}$ Assim é chamada a National Grange of the Order of Patrons and Husbandry (Granja Nacional da Ordem dos Chefes e Maridos), uma organização estadunidense fundada em 1867 para fomentar a união de famílias de pequenos agricultores, comerciantes e artesãos, e promover sua proteção e crescimento econômico. Nascida no momento em que a industrialização e a concentração econômica expandiam-se nos Estados Unidos, a Grange era tanto uma organização com funções de preservação cultural tradicional, como também um instrumento de pressão das antigas classes médias rurais sobre o governo. (N. do T.)
} 
acabamos de colher suas plantações, nós somos vagabundos e devemos ir embora."

Há as plantações de hortaliças do Imperial Valley [vale ao sul da Califórnia, a cerca de $190 \mathrm{~km}$ de San Diegol que precisam ser colhidas e empacotadas, capinadas e irrigadas: alfaces, couves-flor, tomates, repolhos. Há diversas plantações por ano para serem colhidas, mas não há tempo nem distribuição suficiente para dar aos migrantes trabalho permanente. Os pomares de laranja produzem duas safras por ano, mas a temporada de apanha é curta. Mais ao norte, em Kern County e em San Joaquin Valley, os migrantes são necessários para as uvas, algodão, peras, melões, feijões e pêssegos.

No exterior do vale, próximo de Salinas, Watsonville e Santa Clara, há alfaces, couves-flor, alcachofras, maçãs, ameixas e damascos. Ao norte de San Francisco a produção é de uvas, de frutas decíduas e de lúpulo. O Sacramento Valley precisa de massas de imigrantes para seus aspargos, nozes, pêssegos, ameixas etc. Esses grandes vales, com sua intensa agricultura, demandam sazonalmente a mão-de-obra migrante.

Um tempo antes da apanha começar, há a correria das rodovias, com as famílias em carros abertos correndo para as plantações prontas para a colheita, correndo para serem as primeiras a chegar ao trabalho. Isso se dá desse modo pois tem sido o costume das associações dos agricultores do estado prover, por meio da importação, o dobro da mão-de-obra necessária, para que os salários permaneçam baixos.

Donde a pressa. Se o migrante chegar um pouco atrasado, os postos de trabalho podem estar todos preenchidos e ele terá feito sua viagem por nada. $\mathrm{E}$ isso sem contar as muitas outras coisas que podem acontecer mesmo se ele chegar em tempo. A plantação pode estar atrasada, ou podem ocorrer outras situações como aquela de Nipomo [cidade na parte centro-sul da Califórnia, no Condado de San Luis Obispo], no ano passado, quando doze mil trabalhadores chegaram para colher ervilhas somente para encontrá-las apodrecidas pela chuva. Como os migrantes haviam gasto todos os seus recursos para chegar até aquele campo, eles não conseguiam seguir em frente, 
permanecendo ali e passando fome até que o auxílio do governo foi, tardiamente, direcionado a eles.

Assim eles vão, freneticamente, com a fome em seu encalço.

Nessa série de artigos havemos de tentar ver como os novos migrantes vivem e que tipo de pessoas são, qual seu padrão de vida, o que é feito para eles e por eles, e quais são seus problemas e necessidades. Por enquanto a Califórnia tem sido bem-sucedida na utilização do trabalho migrante; está gradualmente construindo uma estrutura humana que certamente mudará o estado, e que pode, se tratada com a desumanidade e a estupidez com que o foi no passado, destruir o atual sistema de economia agrícola.

Os acampamentos de migrantes espalham-se ao longo de toda a Califórnia. Vejamos, pois, com o que um típico acampamento destes se parece.

Ele está localizado às margens de um rio, próximo a um canal de irrigação ou ao lado de uma estrada onde houver fonte de água disponível. De longe ele parece um lixão, e poderia bem sê-lo, pois o lixão da cidade é a fonte do material com o qual ele é construído. Pode-se ver um amontoado de farrapos sujos e sucata, de casas construídas com gravetos, com latas amassadas ou com papel, e somente olhando de muito perto é que se pode ver que são lares.

Eis uma casa construída por uma família que tentou manter um certo asseio. A casa tem aproximadamente 10 pés por 10 pés, ${ }^{4}$ e foi construída totalmente com papelão. O telhado é pontudo e as paredes foram pregadas a uma moldura de madeira. O chão de terra é varrido, e no canal de irrigação ou no rio lamacento ao lado, a esposa esfrega as roupas sem sabão, tentando enxaguar a lama na água lamacenta. O espírito dessa família ainda não foi aniquilado, pois as crianças, há três delas, ainda possuem roupas, e a família ainda possui três velhas colchas e um colchão ensopado e encaroçado. $\mathrm{O}$

\footnotetext{
${ }^{4}$ Trata-se de uma casa de 3 metros por 3 metros, ou seja, de 9 metros quadrados. (N. do T.)
} 
dinheiro deles, contudo, é necessário demais para a comida para ser usado na compra de sabão ou roupas.

Com a primeira chuva a casa cuidadosamente construída irá se desfazer em uma massa marrom e mole, e em poucos meses as roupas irão se desgastar nos corpinhos das crianças, ao passo que a falta de alimentação irá sujeitar toda a família à pneumonia tão logo o primeiro frio chegue.

Cinco anos atrás essa família tinha cinquenta $\operatorname{acres}^{5}$ de terra e mil dólares no banco; a esposa fazia parte de um círculo de costura ${ }^{6}$ e o homem era membro da Grange. Eles criavam porcos e pombos, plantavam vegetais e frutas para seu próprio consumo, e sua terra produzia o alto milho do Meio-oeste. Agora eles não têm nada.

Se o marido alcançar as colheitas sem atraso e trabalhar o máximo que puder, poderá ganhar quatrocentos dólares esse ano. Mas se qualquer coisa acontecer, se seu velho carro quebrar e ele se atrasar, vindo a perder uma ou duas dessas colheitas, ele terá que alimentar toda a sua família com somente cento e cinquenta dólares.

Mas ainda há orgulho nessa família. Onde quer que eles tenham de se assentar, eles tentam matricular as crianças na escola, e pode ser que elas fiquem matriculadas ali durante um mês antes que eles partam para outra localidade.

Quando esse ponto é atingido, nas feições do marido e sua esposa se começa a ver uma expressão que notar-se-á em todos os rostos: não preocupação, mas um terror absoluto da fome que espreita nas bordas do acampamento. Esse homem tentou cavar um buraco próximo a sua casa e cercálo com um pedaço de aniagem para fazer disso uma latrina, mas ele fará isto somente esse ano. Ele é um recém-chegado, seu espírito, sua decência e seu senso de dignidade ainda não foram aniquilados. No próximo ano ele estará como seu vizinho. Vejamo-no.

\footnotetext{
${ }^{5}$ Trata-se de uma propriedade com pouco mais de 20 hectares. (N. do T.)

6 Os círculos de costura (sewing circles) eram organizações, institucionais ou não, independentes ou vinculadas a alguma paróquia ou associação comunitária, que reuniam mulheres com o propósito, além da costura, de realizar atos de caridade, conversar e servir como espaço de sociabilidade. (N. do T.)
} 
Trata-se de uma família de seis pessoas: um homem, sua esposa e seus quatro filhos. Eles vivem em uma tenda da cor de terra. A podridão tomou a lona, de modo que as abas e os lados estejam em farrapos, sendo mantidos juntos por meio de restos enferrujados do arame que outrora era usado para amarrar fardos. Há uma cama para toda a família, e é um grande forro de colchão jazendo no chão da tenda.

Eles só têm uma colcha e um pedaço de lona para dormir. O arranjo para dormir é inteligente: mãe e pai deitam juntos e as duas crianças deitam entre eles. Então, com a cabeça na outra direção, os dois outros deitam, os menores. Se a mãe e o pai dormirem com as pernas bem abertas, há espaço para as pernas das crianças.

Há mais sujeira por aqui. A tenda está cheia de moscas, agarradas à caixa de maçãs que serve de mesa ou zumbindo por sobre as imundas roupas das crianças, particularmente sobre o bebê, que não é limpo e tampouco banhado já faz alguns dias. Essa família esteve na estrada por mais tempo que aquele o construtor da casa de papel. Não há latrina aqui, mas há uma pequena mata de salgueiros próxima, onde fezes jazem expostas às moscas - as mesmas que estão dentro da tenda.

Duas semanas atrás havia outra criança, um garoto de quatro anos de idade. Durante algumas semanas eles notaram que ele parecia cabisbaixo e que seus olhos pareciam febris. Eles lhe deram o melhor lugar na cama, entre o pai e a mãe, mas uma noite ele teve convulsões e morreu, tendo sido levado pelo carro do médico-legista no dia seguinte. Foi como descer um degrau abaixo.

Eles sabem muito bem que a dieta de frutas, feijão e outras parcas coisas causou sua morte. Ele não tomou leite por meses. Com sua morte opera-se uma mudança na mente dessa família: o pai e a mãe sentem aquela paralisia apática com a qual a mente protege a si mesma de muita tristeza e de muita dor. Esse pai não estará mais preparado para conseguir o máximo de quatrocentos dólares anuais, porque ele não está mais alerta. Ele não mais é rápido na empreitada, e não consegue mais combater a apatia que o dominou. Seu espírito perde o vigor rapidamente. 
A apatia está expressa nos rostos dessa família, e há, ainda, um mal humor que os torna taciturnos. Às vezes eles ainda tentam matricular os filhos mais velhos na escola, mas as pequenas criaturinhas esfarrapadas não irão para lá. Eles se escondem em alguma valeta ou perambulam sozinhos e sem destino até a hora em que devem voltar para as tendas, e o fazem porque na escola são alvo do desprezo. As crianças bem vestidas gritam e zombam deles, os professores são frequentemente impacientes com esse acréscimo a suas tarefas, e os pais das crianças "boas" não querem portadores de doenças nas escolas.

Uma vez o pai dessa família teve uma mercearia, e sua família morava nos fundos dela, de modo que cada criança podia ajudar no balcão. Quando a seca chegou, não havia mais vendas na loja.

Essa é a classe média dos acampamentos de posseiros. Em poucos meses essa família irá passar para a classe mais baixa. A dignidade não existirá mais, e o espírito virará raiva soturna antes de morrer.

Ao lado desta vive outra família, com pai, mãe e três crianças com idades de três a nove anos. O pai construiu uma casa fixando troncos de salgueiro no chão e prendendo nele gravetos, lata, papel velho e tiras de tapete. Alguns galhos foram postos por cima para protegê-la do sol do meio-dia, mas não o protegerão em nada da água. Não há cama aqui. Em algum lugar a família encontrou um grande pedaço de tapete, que está sobre o chão. Para dormir, os membros da família deitam-se no chão e puxam o tapete sobre si.

O filho de três anos tem como vestimenta um saco de aniagem amarrado sobre seu corpo, e a barriga inchada por causa da má nutrição. Ele senta sob o sol, no chão, em frente à casa, e pequenas e pretas moscas de fruta zumbem em círculos, pousando em seus olhos fechados e rastejando para dentro de seu nariz até que ele, debilmente, as espante. As moscas tentam pegar também o muco acumulado no canto dos olhos. Essa criança parece ter as reações de um bebê. No primeiro ano ele teve um pouco de leite, mas nem mais um gole desde então.

Ele morrerá logo. As crianças mais velhas poderão, talvez, sobreviver. Quatro noites atrás a mãe teve um bebê na tenda, sobre o tapete sujo. Ele 
nasceu morto, o que até foi bom, visto que sua mãe não poderia amamentá-lo, uma vez que sua dieta não lhe dá condições de produzir leite.

Após ter ele nascido e ter sua mãe visto que ele estava morto, ela rolou para o lado e ficou deitada inerte por dois dias. Ela está de pé hoje, cambaleando por aí. O último bebê, nascido há menos de um ano, viveu uma semana. Os olhos dessa mulher têm o aspecto vidrado e distante característico dos olhos de um sonâmbulo. Ela não lava mais roupas. O impulso que a fazia manter o asseio lhe foi arrancado, ela não tem mais a energia para tal. O marido fora um meeiro, mas não conseguiu continuar sendo. Agora ele perdeu até mesmo a vontade de falar. Ele não olhará diretamente para você, porque isso requer vontade, e vontade precisa de força. Ele é um mau trabalhador pela mesma razão. Leva muito tempo para que ele tome uma decisão, de modo que ele esteja sempre atrasado ao se mudar e, consequentemente, atrasado para chegar aos campos. O melhor salário que ele consegue, quando encontra trabalho - isto é, não frequentemente -, é um dólar por dia.

As crianças nem sequer vão ao arvoredo de salgueiros. Eles se agacham onde estão e depois chutam um pouco de poeira por cima. O pai sabe vagamente que existem vermes na lama ao longo da margem do rio. Ele sabe que as crianças irão se contaminar andando por lá de pés descalços, mas ele não tem nem a vontade nem a energia para impedi-las. Coisas demais aconteceram a ele. Essa é a classe mais baixa do acampamento.

Isso é o que o homem na tenda será em seis meses; o que o homem na casa de papel com seu telhado pontudo será dentro de um ano, após suas casas terem sido desmanchadas e seus filhos terem sucumbido a doenças ou morrido, depois que a perda de dignidade e espírito o tiver reduzido a uma espécie de subumanidade.

Estranhos prestativos não são bem recebidos nesse campo. O xerife local ataca de tempos em tempos, em busca de um homem procurado. Se houver algum problema com relação à mão-de-obra, os vigilantes podem queimar as pobres casas. Assistentes sociais e pesquisadores têm feito estudos sobre essa situação. Eles estão arquivados e abertos para inspeção. Essas 
famílias têm sido questionadas várias e várias vezes a respeito de suas origens e número de filhos, vivos e mortos. As informações foram recolhidas e arquivadas. E é só isso. Foi feito tantas vezes e tão pouco tem disso resultado.

Ainda há uma outra maneira deles conseguirem atenção. Deixe uma epidemia surgir, digamos febre tifóide ou escarlatina, e o médico do governo virá ao acampamento e encaminhará imediatamente os infectados para uma casa de controle de pragas. Mas a subnutrição não é infecciosa, bem como não o é a disenteria, que é quase uma regra entre as crianças.

O hospital do condado não tem leitos para sarampo, caxumba, coqueluche; e essas são quase sempre fatais para crianças enfraquecidas pela falta de comida. E, ainda que ouçamos muito a respeito das clínicas gratuitas para os pobres, essas pessoas não sabem como conseguir o auxílio, o que faz com que não o consigam. Uma vez que a maioria dos contatos com as autoridades foram dolorosos para eles, eles preferem não se arriscar.

Este é o acampamento dos migrantes. Alguns são um pouco melhores, outros bem piores. Eu descrevi três famílias típicas. Em alguns acampamentos existem até trezentas famílias como essas. Alguns são tão distantes da água que ela tem de ser comprada por cinco cents o balde.

Se esses homens roubam e se há o crescimento, entre eles, de uma suspeita e um ódio das pessoas bem vestidas e bem alimentadas, a razão para tal não deve ser procurada em sua origem nem em qualquer tendência de seu caráter à fraqueza.

Quando, ao longo da temporada, o pequeno fazendeiro necessita de um fluxo de trabalhadores temporários, ele geralmente os recruta nos acampamentos de migrantes. Por pequeno fazendeiro entendo o dono de uma propriedade de 5 a 100 acres, $^{7}$ que opera e supervisiona sua própria fazenda.

\footnotetext{
7 Tratam-se, portanto, de propriedades de tamanho entre pouco mais de 2 hectares até aproximadamente 40 hectares. (N. do T.)
} 
Fazendas desse tamanho são as que mais se utilizam da mão-de-obra dos notórios acampamentos de migrantes. Algumas dessas fazendas possuem pequenas porções de terra onde os trabalhadores podem armar seus abrigos. A água é fornecida, e, às vezes, até mesmo um banheiro. Raramente há alguma instalação para banhos. Um pequeno fazendeiro não tem condições de arcar com o dispêndio necessário para manter um acampamento sanitário.

Além do mais, os pequenos fazendeiros têm medo de permitir que grupos de migrantes acampem em suas terras, e também não gostam do lixo que fica quando eles deixam sua propriedade para seguir adiante. No geral, as relações entre os migrantes e os pequenos fazendeiros são amigáveis e compreensivas.

Em muitas greves agrícolas na Califórnia o pequeno fazendeiro cerrou fileiras com os migrantes contra os poderosos grupos de grandes proprietários especuladores. Os trabalhadores percebem que o problema do pequeno fazendeiro não é diferente do seu próprio.

Temos o exemplo de San Joaquin Valley [vale na parte central da Califórnia] há dois anos, em que um pequeno fazendeiro ficou do lado dos trabalhadores numa greve do algodão. O grupo de fazendeiros especuladores, que possui estreitos laços com as companhias de energia, determinou que a energia dessa fazenda, que era utilizada para a irrigação, fosse cortada, de modo a ameaçá-la. Mas os grevistas cercaram e protegeram o poste de energia, recusando-se a permitir que esse fosse desligado. Incidentes dessa natureza ocorrem frequentemente.

O pequeno fazendeiro tira sua mão-de-obra dos acampamentos de migrantes e dos acampamentos estaduais e federais, os quais serão tratados posteriormente. ${ }^{8}$ Os grandes fazendeiros, por outro lado, geralmente mantêm seus próprios acampamentos de trabalhadores.

\footnotetext{
${ }^{8}$ Os artigos subsequentes de The harvest gypsies (infelizmente não incluídos aqui) tratam dos acampamentos estaduais e federais onde eram abrigados parte desses trabalhadores migrantes. Uma noção muito boa sobre a opinião e as impressões de Steinbeck sobre esses acampamentos pode ser obtida no capítulo 25 do romance As vinhas da ira. (N. do T.)
} 
Os grandes fazendeiros da Califórnia são organizados tão estreitamente, e têm sua política de trabalho tão bem definida quanto as indústrias, o setor de transportes, os bancos e os serviços de utilidade pública. De fato, organizações tais como a Associated Farmers Inc. ${ }^{9}$ tem como membros e conselho oficiais de bancos, editores de jornais e políticos. Através de estreita associação com a Câmara Estadual de Comércio, eles têm ligações e contato com grupos de donos de navios, corporações de serviços públicos e companhias de transporte.

Os membros dessas organizações de fazendeiros especuladores são de vários tipos: proprietários de grandes porções de terra que não vivem nelas, bancos que adquiriram terras por embargo (como por exemplo os tremendos títulos e posses do Bank of America no San Joaquin Valley) e fazendas industriais que têm acionistas, conselho de diretores e a usual estrutura corporativa. Tais fazendas são invariavelmente administradas por superintendentes cujas políticas com relação ao trabalho lhes são direcionadas de cima. O poder de organizações como a Associated Farmers Inc. se estende para muito além do controle de suas próprias terras.

É raro que na Califórnia um pequeno fazendeiro esteja apto a plantar e cultivar sua safra sem ter de recorrer a empréstimos de bancos ou de companhias financeiras. E uma vez que esses bancos e companhias financeiras são, a um tempo, membros das poderosas associações de grandes produtores e fonte dos empréstimos para o plantio e cultivo, a força de suas políticas sobre os pequenos fazendeiros pode ser facilmente entendida: recusar-se a obedecêlas é arriscar um embargo e uma futura recusa do necessário empréstimo para o plantio.

Esses fortes grupos, portanto, não representam necessariamente o sentimento geral com relação à mão-de-obra, mas, estando aptos a obter espaço nos jornais e no rádio, conseguem não somente representar-se como se fossem todo o corpo de agricultores da Califórnia, mas também impor suas políticas a um grande número de pequenos fazendeiros.

\footnotetext{
${ }^{9}$ Trata-se da organização dos grandes fazendeiros californianos, fundada em 1934 para opor-se às greves de trabalhadores rurais e à sua crescente organização política. (N. do T.)
} 
As propriedades controladas por esses fazendeiros especuladores costumam ter casas para seus trabalhadores migrantes, casas pelas quais eles cobram um aluguel de três a quinze dólares mensais. Na maioria dos lugares não é permitido a um trabalhador se recusar a pagar o aluguel: se ele quiser trabalhar, deverá morar em uma dessas casas, e o aluguel será descontado diretamente de seu primeiro pagamento.

Vejamos como são essas moradias, não aquelas casas de quinze dólares que somente podem ser alugadas aos capatazes, ${ }^{10}$ mas as casas de três a cinco dólares que são impostas aos trabalhadores.

As casas, barracos de apenas um cômodo, medem 10 por 12 pés ${ }^{11}$ e não possuem tapete, água ou cama. Em um dos cantos há um pequeno fogão à lenha. A água deve ser carregada de uma torneira localizada no fim da rua. Lá também há uma latrina ou um banheiro com um tanque séptico para servir a cem ou cento e cinquenta pessoas. Um típico e razoável rancho de Kern County tinha uma instalação para banho com um único chuveiro sem aquecimento, que servia a todos os moradores do bloco, cuja capacidade era de quatrocentas pessoas.

A chegada do migrante em um rancho como esse é mais ou menos a seguinte: lhe é designada uma casa para sua família; ele pode ter de três a seis filhos, mas eles devem todos morar no mesmo e único cômodo da casa. Ele encontra todo o rancho pesadamente policiado por funcionários-delegados, designados para essa função.

A vontade do dono do rancho, portanto, é lei; pois esses funcionáriosdelegados estão sempre prontos a agir com suas vistosas armas, e um desacordo com eles constitui resistência a um oficial. Uma olhada rápida na lista de migrantes baleados ao longo de um único ano na Califórnia por "resistir a um

\footnotetext{
${ }^{10}$ O termo, no original, é "pushers", e se refere aos chefes mais diretos dos trabalhadores, que ocupam em relação a eles praticamente o mesmo papel que o superintendente em relação aos fazendeiros. A opção por "capatazes", dadas as questões que Steinbeck discute e o tom que adota, bem como pelo sentido histórico que o termo possui em português, nos pareceu torná-lo opção adequada. (N. do T.)

${ }^{11}$ Tais casas, portanto, possuem uma área de aproximadamente 11 metros quadrados. (N. do T.)
} 
oficial" dará uma boa ideia da casualidade com que esses "oficiais" atiram nos trabalhadores.

A próxima chegada daquele migrante supramencionado a um rancho será, provavelmente, sem fundos. Seus recursos foram exauridos para chegar até aqui. Mas, na maioria dos grandes ranchos, ele encontrará uma mercearia mantida pela administração do rancho na qual ele goza de crédito. Em virtude disto, ele deve trabalhar um segundo dia para pagar pelo seu primeiro, e assim sucessivamente: ele está continuamente em débito, logo, deve trabalhar. Há somente um tipo de propriedade que é passível de servir como garantia ao débito, o carro. Contudo, se os homens solteiros podem pedir carona ou andar clandestinamente para ir de colheita à colheita, o mesmo não se dá com o pai de família, que morrerá de fome se ficar sem seu carro. Por conta disto, lhe resta continuar trabalhando.

No campo ele será continuamente assistido pelo capataz, o chefe do campo, e em muitos casos, por um trabalhador responsável por ditar o ritmo. Durante a apanha, aquele que dita o ritmo estará sempre uma árvore a frente, e se o trabalhador não o acompanhar, está demitido. É comum que as fileiras colhidas por aquele trabalhador que marca o ritmo tenham de ser refeitas novamente depois, visto que sua agilidade tem mais função de controle dos demais do que de esmero na lida.

Nos grandes ranchos não há qualquer esforço para proporcionar lazer ou entretenimento para os trabalhadores. Qualquer tentativa de congregação por parte destes é rapidamente desmantelada pelos funcionários-delegados, pois teme-se que, se for permitido aos trabalhadores congregar-se, eles irão se organizar politicamente, e isso é algo que os grandes não permitirão a custo algum.

A atitude do empregador do grande rancho é de ódio e suspeita, e seu método é a ameaça das armas dos funcionários-delegados. Os trabalhadores são arrebanhados como animais, e todos os recursos possíveis são empregados para fazê-los se sentirem inseguros e inferiores. À menor suspeita de que os homens estão se organizando, eles são expulsos do rancho sob a mira das armas. Os 
donos dos grandes ranchos sabem que se alguma organização se erguer, haverá gastos com banheiros, chuveiros, condições de vida decentes e aumento dos salários.

A atitude dos trabalhadores dos ranchos é muito parecida com a do dono do rancho: de ódio e de suspeita. O trabalhador se vê cercado à força e sabe que pode ser morto sem receio por parte do empregador, tendo poucos recursos aos quais recorrer perante à lei. Em face disto, ele acaba por se refugiar numa quietude mal-humorada e tensa. Para poder alimentar sua família, o trabalhador é incapaz de recusar o crédito que lhe é concedido pelo fazendeiro, ainda que conheça perfeitamente as razões por detrás dele.

Há poucos ranchos grandes na Califórnia que mantém para os trabalhadores "casas modelo" bem pintadas e dotadas de algumas conveniências. Esses ranchos costumam cobrar cinco dólares por mês por uma casa de um cômodo e pagam 33,3\% menos que o salário predominante.

A política de trabalho dessas grandes propriedades operadas à distância criou um resultado inevitável. Geralmente há guardas no portão, as estradas são patrulhadas e permissões para inspecionar o local nunca são concedidas. Parece até que, tendo criado a atitude repressiva com relação ao trabalho de que necessitam para poder produzir, os diretores ficaram aterrorizados com sua criatura. O medo dita um aumento da repressão, um aumento no número de guardas e a sugestão perene de que o rancho está armado para lutar.

Num acampamento de migrantes, a dignidade dos homens é atacada e nenhuma confiança lhes é concedida. Eles estão cercados como se fossem iniciar uma revolta a qualquer momento. Parece, no entanto, que método mais certeiro para que eles iniciassem uma revolta não poderia existir: a repressão resulta, inevitavelmente, em irrupções de revolta desorganizada que devem ser derrubadas pela força e pelo aumento da intimidação.

Os grupos de grandes proprietários consideraram a lei inadequada a seus interesses, e se tornaram tão poderosos que as acusações de ataque, lesão física, incitação à revolta, sequestro e punição não podem ser movidas contra eles nas cortes sob seu controle. 
A atitude de associações de grandes proprietários com relação ao trabalho é melhor exemplificada pelo senhor Hugh T. Osburne, um membro do Conselho de Supervisores de Imperial County, membro também do grupo Imperial Valley Associated Farmers. Diante do comitê judiciário da Assembleia da Califórnia ele disse: "No Imperial Valley nós não precisamos dessas leis de criminalização do sindicalismo. Elas são para os outros condados, que não sabem como lidar com esses assuntos. Nós não precisamos delas porque encontramos nossa própria maneira de lidar com isso. Não teremos outros desses julgamentos, temos um jeito melhor. Julgamentos custam muito caro."

O "jeito melhor", conforme aceito pelos grandes produtores de Imperial Valley, inclui um sistema de terrorismo que seria estranho mesmo às nações fascistas do mundo. A estúpida política do grande proprietário e dos fazendeiros especuladores tem gerado somente inquietação, tensão e ódio na Califórnia. Uma continuação dessa política constitui uma ameaça criminosa à paz no estado.

Recebido em: 19 de agosto de 2020

Aceito em: 1 de outubro de 2020 